\title{
PENINGKATAN NETWORK LIFETIME PADA WIRELESS SENSOR NETWORK MENGGUNAKAN CLUSTERED SHORTEST GEOPATH ROUTING (C-SGP) PROTOCOL
}

\author{
Listyanti Dewi Astuti ${ }^{1}$, Waskitho Wibisono² \\ ${ }^{1,2}$ Institut Teknologi Sepuluh Nopember \\ Email: ${ }^{1}$ listyantidewi@gmail.com, ${ }^{2}$ waswib@gmail.com
}

(Naskah masuk: 15 Mei 2017, diterima untuk diterbitkan: 14 Agustus 2017)

\begin{abstract}
Abstrak
Jaringan sensor nirkabel atau wireless sensor network adalah sebuah jaringan yang terdiri dari banyak sensor node, yang berfungsi untuk memindai fenomena tertentu di sekitarnya. Masing-masing sensor node pada umumnya memiliki sumber daya energi berupa baterai, yang memiliki kapasitas terbatas, sehingga diperlukan sebuah teknik untuk meningkatkan network lifetime pada wireless sensor network. Pada penelitian ini, protokol routing Shortest Geopath (SGP) dikembangkan menjadi sebuah protokol routing berbasis cluster, dengan membagi jaringan menjadi beberapa cluster yang masing-masing memiliki cluster head. Pembentukan cluster dilakukan dengan menggunakan informasi geografis area jaringan untuk membentuk cluster berupa segi enam (hexagon). Penentuan cluster head dilakukan dengan mencari node yang memiliki posisi geografis paling dekat dengan titik tengah area cluster. Pengiriman data dilakukan dengan sistem adaptif, dimana data dengan prioritas rendah dikirim setelah mencapai jumlah data tertentu, dan dikirim setelah melalui proses rata-rata sehingga hanya menghasilkan satu data untuk dikirim. Data dengan prioritas tinggi, dikirim langsung menuju sink. Hasil simulasi menunjukkan peningkatan network lifetime hingga 25,68\% jika dibandingkan dengan protokol routing Shortest Geopath yang tidak melalui proses clustering.
\end{abstract}

Kata kunci: Network Lifetime, clustering, Shortest Geopath Routing, Wireless Sensor Network

\begin{abstract}
Wireless sensor network is a type of network consisting many sensor nodes. Each sensor node has a limited battery capcity, which most of the time, cannot be recharged. Thus, researches on extending network lifetime of wireless sensor networks are indispensable. This research proposed a cluster-based routing protocol, which adds clustering phase to the Shortest Geopath Routing (SGP) protocol. Cluster formation is done by forming imaginary hexagons using geographical informations about the network. Node which is nearest to the center point of the hexagon is appointed to be cluster head. Data transmissions are controlled by an adaptive mechanism. Low priority datas are only sent after the responsible node already obtained a specified number of datas. The datas, then, are being averaged and wrapped into a single data to be sent to the sink. Very high priority datas are, however, directly sent to the sink without passing the averaging process. It reduces the number of transmissions, which eventually help extending the network lifetime together with the clustering mechanism. Simulation results showed that the proposed protocol increases network lifetime up to $25.68 \%$ compared to the original un-clustered Shortest Geopath Routing protocol.
\end{abstract}

Keywords: Network Lifetime, clustering, Shortest Geopath Routing, Wireless Sensor Network

\section{PENDAHULUAN}

Jaringan sensor nirkabel (wireless sensor network/WSN) adalah kumpulan dari piranti-piranti sensor nirkabel (sensor nodes) yang pada umumnya digunakan untuk merekam data-data mengenai fenomena tertentu dalam suatu wilayah. Sensor nodes memiliki kemampuan komputasi dan komunikasi yang terbatas. Pola komunikasi umum pada WSN adalah pengiriman data hasil pemindaian (sensing) fenomena menuju base station atau sejumlah node yang sudah ditentukan sebagai penghimpun data. Base station melakukan request kepada sensor nodes, yang berisi query tentang fenomena yang akan dikoleksi, interval sampling, dan waktu total sampling. (Kaur \& Amarvir, 2016)

Sensor nodes memiliki sumber daya energi yang terbatas. Pengisan ulang baterai pada umumnya tidak bisa dilakukan karena posisi sensor nodes yang dapat berada pada kondisi wilayah yang ekstrim, seperti lokasi bencana alam. Oleh karena itu, masa hidup WSN (wireless sensor network life time) perlu ditingkatkan agar manfaat WSN dapat dirasakan lebih lama. Penelitian terkini dalam meningkatkan masa hidup WSN cenderung dilakukan dengan mengembangkan protokol-protokol energy aware 
routing yang melibatkan agregasi data, clustering, dan scheduling yang diharapkan mampu menghemat sumber daya energi dari sensor node.

Geographic routing (GR) atau penentuan rute berdasarkan posisi geografis diperkenalkan untuk mengatasi keterbatasan protokol routing berbasis topologi. Protokol geographic routing mengandalkan informasi lokasi fisik node dalam WSN yang diperoleh dari location service (misalnya: GPS). Dengan memanfaatkan informasi posisi geografis, GR tidak perlu melakukan pemeliharan routing table, dan bahkan bisa berjalan tanpa routing table sama sekali (Maghsoudlou, StHilaire, \& Kunz, 2011).

Dalam penelitian ini dikembangkan protokol routing berbasis geografis dengan menambahkan tahap clustering pada protokol Shortest Geopath Routing (SGP), sehingga menjadi protokol baru yang diberi nama Clustered Shortest Geopath Routing Protocol (C-SGP). Pengembangan ini diharapkan mampu meningkatkan network lifetime dari Wireless Sensor Network (WSN) sehingga kemampuan pemindaian data dapat berjalan dengan efisien, tahan lama, terhindar dari kegagalan jaringan yang disebabkan oleh habisnya sumber daya energi node sebelum waktunya, dan memenuhi target yang ditentukan.

\section{PENELITIAN TERKAIT}

Beberapa protokol routing berbasis geografis telah diperkenalkan sejak tahun 1980, misalnya Greedy Routing yang dikembangkan oleh Takagi dan Kleinrock (1980) yang menghitung semua jalur berdasarkan jarak Euclidean dari sensor node menuju sink node, lalu memilih jalur yang paling sesuai. Protokol-protokol terbaru pada umumnya merupakan pengembangan dari protokol Greedy Routing, dengan cara menambahkan modifikasi tertentu sesuai pertimbangan delay, troughput, energi, dan lain-lain.

Dari beberapa protokol geographic routing yang telah dikembangkan, Shortest Geopath Routing (SGP) merupakan salah satu protokol yang banyak diteliti pada WSN, karena menjanjikan packet delivery ratio yang baik dengan waktu delay yang rendah. Selain itu, protokol SGP tidak memerlukan komputasi yang rumit, sehingga cocok untuk diterapkan pada WSN yang memiliki kemampuan komputasi terbatas. (Ghica, et.al., 2007).

Protokol SGP dikembangkan oleh peneliti dengan menambahkan tahap clustering dan mengontrol pengiriman data agar sensor node mampu mengirim data sesuai prioritas. Clustering dilakukan dengan memanfaatkan informasi geografis masing-masing sensor node. Teknik clustering yang menjadi rujukan peneliti dapat dilihat pada Tabel 1 .
Tabel 1. Penelitian Terkait

\begin{tabular}{|c|c|c|}
\hline Referensi & $\begin{array}{c}\text { Penelitian } \\
\text { Terkait }\end{array}$ & Keterangan \\
\hline $\begin{array}{l}\text { (Lee \& Kao, } \\
\text { 2016) }\end{array}$ & $\begin{array}{l}\text { Teknik } \\
\text { clustering } \\
\text { menggunakan } \\
\text { LEACH (Low } \\
\text { Energy } \\
\text { Adaptive } \\
\text { Clustering } \\
\text { Hierarchy). }\end{array}$ & $\begin{array}{l}\text { Mampu } \\
\text { meningkatkan } \\
\text { network } \\
\text { lifetime WSN } \\
\text { hanya pada } \\
\text { jaringan- } \\
\text { jaringan yang } \\
\text { padat, karena } \\
\text { cluster head } \\
\text { dipilih secara } \\
\text { acak bergilir } \\
\text { yang } \\
\text { mengakibatkan } \\
\text { beberapa node } \\
\text { terisolasi }\end{array}$ \\
\hline $\begin{array}{l}\text { (Jannu \& } \\
\text { Jana, 2014) }\end{array}$ & $\begin{array}{l}\text { Teknik routing } \\
\text { berbasis } \\
\text { informasi } \\
\text { geografis } \\
\text { dengan } \\
\text { membagi } \\
\text { jaringan dalam } \\
\text { beberapa } \\
\text { cluster yang } \\
\text { berbentuk } \\
\text { persegi empat. }\end{array}$ & $\begin{array}{l}\text { Bentuk cluter } \\
\text { kurang sesuai } \\
\text { dengan area } \\
\text { transmisi } \\
\text { sensor node } \\
\text { yang berbentuk } \\
\text { lingkaran. }\end{array}$ \\
\hline
\end{tabular}

\subsection{Network Lifetime}

Network lifetime atau masa hidup sebuah jaringan sensor memiliki berbagai definisi. Masingmasing definisi memiliki batasan dan belum ada yang bisa diterapkan pada semua kriteria jaringan. Penelitian awal yang merumuskan network lifetime sebagai rentang waktu sejak dimulainya transmisi data yang pertama hingga node terakhir mati dikemukakan oleh Tian dan Georganas (2002). Namun pada kenyataannya, sebuah jaringan sensor sudah tidak bisa mengirim data pemindaian, meskipun belum semua node mati.

Definisi berikutnya yang lebih realistis dikemukakan seiring dengan berkembangnya metode routing berbasis cluster. Soro dan Heinzelman (2005) menyatakan bahwa network lifetime adalah waktu hingga cluster head yang pertama mati. Definisi ini menjadi tidak relevan ketika protokol clustering mulai mampu menangani perubahan topologi dengan mengganti cluster head. Pengertian lain dari network lifetime didefinisikan sebagai waktu jaringan mulai mengirimkan data hingga $\alpha$ persen dari total sensor node mati (Rajagopalan \& Varshney, 2006). Dalam beberapa kasus pada jaringan sensor nirkabel yang sangat mengutamakan lama waktu kemampuan operasi pada salah satu node sensor, lifetime didefinisikan sebagai waktu sensor node yang pertama mengalami kehabisan energi untuk beroperasi. Definisi ini digunakan oleh peneliti dalam 
mengevaluasi kinerja protokol CSGP, karena skenario yang dijalankan sangat mengutamakan kemampuan operasi pada setiap sensor node. Jika salah satu sensor node mati, maka data yang diterima oleh sink menjadi tidak lengkap karena ada wilayah yang tidak terdeteksi suhunya.

Network lifetime menjadi karakteristik utama pada saat melakukan evaluasi kinerja sebuah WSN. Bahkan ukuran quality of service dapat menurun dengan pertimbangan network lifetime. Network lifetime yang baik berpengaruh secara langsung dalam ketersediaan data hasil pemindaian dan penghematan biaya yang diperlukan untuk pemasangan baterai pada sensor node (Dietrich \& Dressler, 2009).

\section{METODE}

Pengembangan protokol routing C-SGP dilakukan dengan memodifikasi protokol routing SGP, meliputi penambahan tahap clustering, mengubah jalur routing, dan membuat proses pengiriman adaptif.

\subsection{Tahap Clustering}

Masing-masing node memiliki area jangkauan transmisi berbentuk lingkaran dengan jari-jari $\mathrm{R}$, di mana $\mathrm{R}$ sama dengan jangkauan sinyal terkecil dari node, dikurangi konstanta c. Dengan mempertimbangkan hal tersebut, maka cluster pada C-SGP diimplementasikan secara geografis dengan membagi wilayah menjadi sejumlah $\mathrm{k}$ cluster, dan masing-masing cluster berbentuk hexagon seperti divisualisasikan pada Gambar 1.

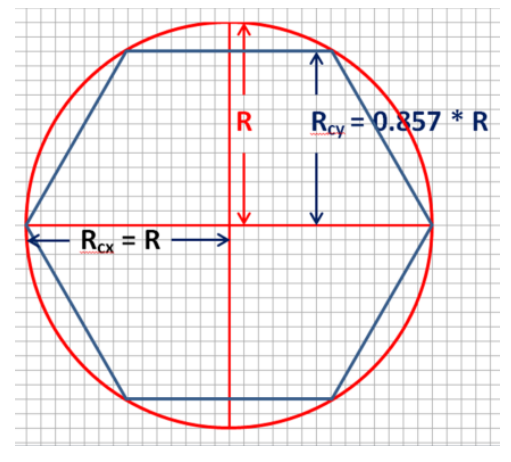

\section{Gambar 1. Bentuk Cluster}

Lingkaran berwarna merah adalah area jangkauan transmisi node yang sebenarnya, dengan asumsi bahwa node berada tepat di tengah lingkaran. Jika node tersebut menjadi cluster head, maka seluruh node tetangganya akan berada satu langkah dari cluster head. Sehingga, titik tengah lingkaran merupakan posisi yang paling ideal untuk cluster head.

Bangun hexagon berwarna biru didesain dengan luas yang lebih kecil dari luas jangkauan transmisi minimal node yang sebenarnya. Namun seluruh sudut cluster menyentuh sisi lingkaran. Hal ini dilakukan untuk menghindari adanya node yang posisinya di luar jangkauan, namun ditentukan untuk menjadi anggota cluster tersebut. Karena luas cluster lebih kecil dari luas jangkauan transmisi, maka cluster diberi nilai Rcy (jarak dari titik tengah ke koordinat $\mathrm{Y}$ tertinggi dan terendah) dan Rcx (jarak dari titik tengah ke koordinat $\mathrm{X}$ tertinggi dan terendah).

Nilai Rcx sama dengan nilai R, karena sudut samping cluster bersentuhan dengan sisi samping lingkaran, sehingga jarak dari titik tengah cluster ke koordinat $\mathrm{X}$ tertinggi dan terendah adalah sama dengan panjang jari-jari lingkaran. Sedangkan nilai Rcy lebih rendah dari $\mathrm{R}$, sehingga dihitung ukuran Rcy secara proporsional, yaitu $85.7 \%$ dari ukuran R. Dengan demikian, maka panjang dan lebar cluster adalah dua kali nilai Rcx dan Rcy.

Tata letak cluster pada area WSN dapat dilihat pada Gambar 2, di mana cluster diformasikan menjadi baris dan kolom. Penentuan jumlah baris (r) dan kolom (c) didapat dari membagi nilai panjang (p) dan lebar (1) area WSN dengan nilai Rcx dan nilai Rcy seperti pada persamaan (1) dan (2).

$$
\begin{aligned}
& r=l /(2 \times R c y)+1 \quad \ldots \ldots \ldots(1) \\
& c=p /(2 \times R c x)+1
\end{aligned}
$$

$$
\begin{aligned}
& \text { Keterangan: } \\
& r \quad=\text { jumlah baris } \\
& c \quad=\text { jumlah kolom } \\
& l \quad=\text { lebar area WSN } \\
& p \quad=\text { panjang area WSN } \\
& R c x=\text { separuh panjang cluster } \\
& R c y=\text { separuh tinggi cluster }
\end{aligned}
$$

Dari jumlah baris dan kolom, didapat jumlah cluster (nk) sesuai persamaan (3).

$$
n k=r * c
$$

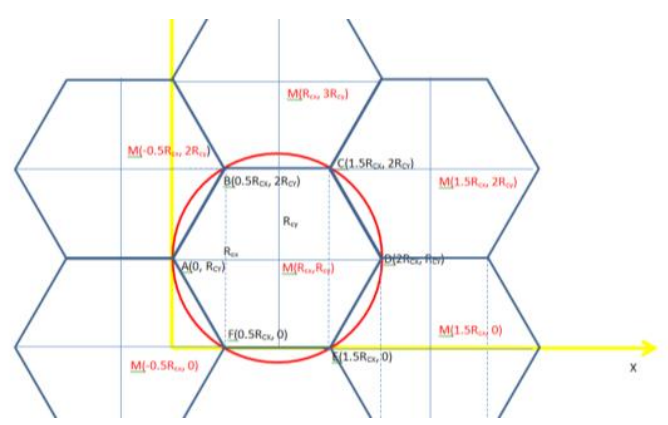

Gambar 2. Tata Letak dan Penentuan Titik Tengah Cluster

Titik tengah cluster merupakan koordinat yang paling strategis untuk penempatan cluster head. Namun jika tidak ada node yang berada persis di tengah cluster, maka node yang posisinya paling dekat dengan titik tengah akan dijadikan sebagai 
cluster head. Penentuan koordinat titik tengah $(M)$ untuk beberapa cluster pertama dapat divisualisasikan seperti pada Gambar 2.

Dari Gambar terlihat bahwa kenaikan nilai koordinat $\mathrm{X}$ untuk setiap titik $M$ pada baris yang sama ada sebesar $1.5 \times R c x$ dan bersifat tetap pada baris-baris berikutnya. Sehingga nilai koordinat $\mathrm{X}$ untuk setiap titik $M$ dapat dihitung dengan persamaan (4).

$M_{(\text {current } x)}=M_{(\text {previous } x+1.5 * R c x)}$

Pada posisi kolom 0 atau genap, nilai $\mathrm{M}(\mathrm{y})$ bernilai sama pada baris yang sama, dan naik sebesar $2 \times R c y$ pada kolom yang sama seperti pada persamaan (5).

$M_{(\text {current } y) \mid \text { genap }}=M_{(\text {previous } y+2 * R c y) \text { genap }}$

Pada posisi kolom ganjil, nilai $M(y)$ bernilai sama pada baris yang sama, dan naik sebesar $2 \times R c y$ pada kolom yang sama, namun lebih tinggi sebesar $R c y$ jika dibandingkan dengan nilai $M(y)$ pada posisi kolom genap.

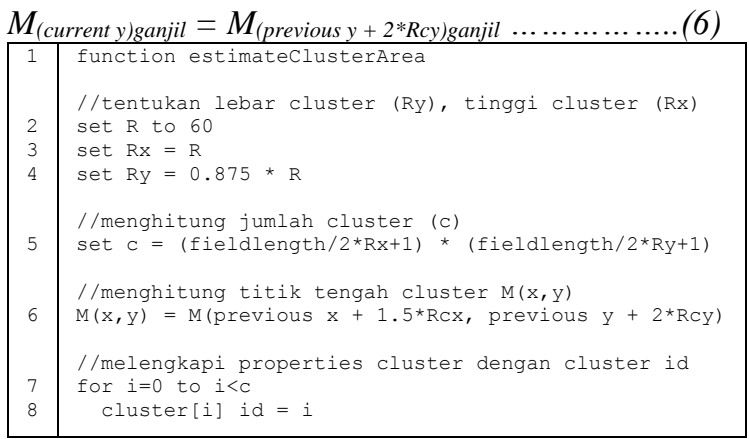

Pseudocode 1. Pembentukan Cluster

\subsection{Pemilihan Cluster Head}

Setelah didapatkan koordinat titik tengah dari masing-masing cluster, maka masing-masing sensor node mulai melakukan pemindaian. Sebelum mengirim data, setiap sensor node mencari node yang paling dekat posisinya dengan titik $\mathrm{M}$ pada masing-masing cluster. Semakin dekat posisi node terhadap titik tengah cluster, maka semakin banyak pula node yang dapat dijangkau pada cluster tersebut. Algoritma penentuan cluster head dapat dilihat pada Pseudocode 2.

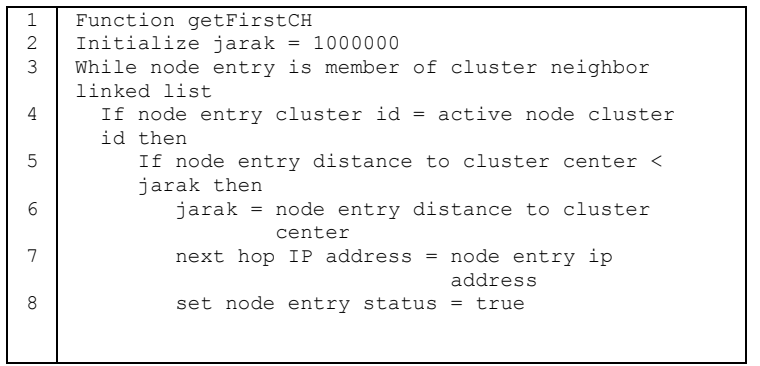

Pseudocode 2. Menentukan Cluster Head

\subsection{Proses Pengiriman Data}

Modifikasi berikutnya adalah pembuatan mekanisme penanganan pengiriman pesan yang adaptif sesuai dengan prioritas pesan. Jika data yang terdeteksi adalah data dengan prioritas tinggi (P1), maka data tersebut akan langsung dikirim menuju sink. Jika data yang terdeteksi adalah data dengan prioritas sedang ( $\mathrm{P} 2)$, maka node tersebut akan menyimpan data hingga 60 data. Setelah tercapai 60 data, maka node akan melakukan proses agregasi data dengan mengambil rata-rata dari keseluruhan data yang tertampung, dan mengirim hasil rata-rata data ke sink. Untuk data dengan prioritas rendah (P3), maka ditampung hingga 300 data. Hal ini akan mengurangi banyak data yang ditransmisikan, sehingga membantu mengurangi penggunaan sumber daya energi. Algoritma proses pengiriman data dituliskan pada Pseudocode 3.

\subsection{Pembentukan Jalur Routing C-SGP}

Secara garis besar, protokol routing Shortest Geopath menggunakan informasi geografis dari node untuk melakukan penentuan jalur. Dimisalkan sebuah node $A$ akan melakukan transmisi data ke node $B$. Maka node $A$, memilih salah satu node tetangganya yang memiliki jarak geografis paling dekat dengan node $B$, lalu mengirimkan data ke node tetangga yang terpilih tersebut. Proses tersebut berulang hingga data sampai ke node $B$, seperti diilustrasikan pada Gambar 3.

Pada protokol routing yang diusulkan, jalur routing dirubah sehingga setiap node akan mengirimkan data menuju cluster head di dalam cluster yang sama, kemudian cluster head meneruskan data menuju sink dengan menggunakan protokol routing SGP.

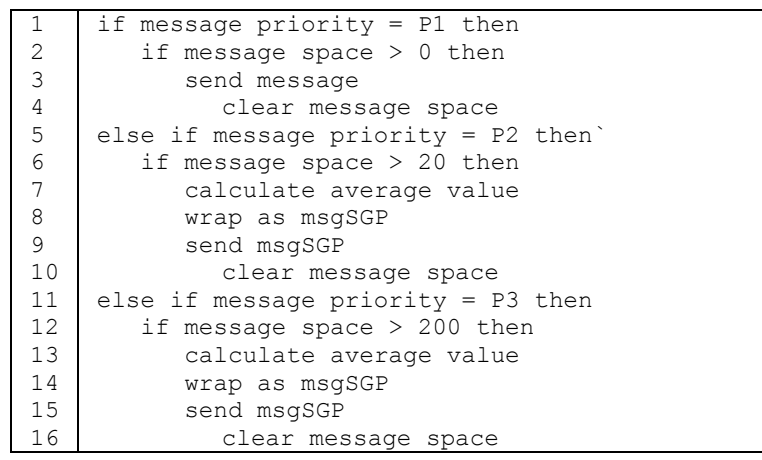

Pseudocode 3. Menentukan Mekanisme Pengiriman

\subsection{Spesifikasi Sensor dan Parameter Uji \\ Pengujian dilakukan di lingkungan simulator SIDnet-SWANS (Simulator and Integrated Development Platform for Sensor Networks Applications), yang berjalan di atas JiST- SWANS (Java in Simulation Time - Scalable Wireless Ad Hoc Network Simulator). Spesifikasi node dan parameter uji dicantumkan pada Tabel 2.}


Tabel 2. Spesifikasi Node dan Parameter Uji

\begin{tabular}{|l|l|l|}
\hline No & \multicolumn{1}{|c|}{ Keterangan } & \multicolumn{1}{c|}{ Detail } \\
\hline 1 & Radio Bandwidth & $40000 \mathrm{~Hz}$ \\
\hline 2 & Sampling interval & 3 seconds \\
\hline 3 & Penempatan node & Random \\
\hline 4 & $\begin{array}{c}\text { Konsumsi baterai } \\
\text { - Active mode }\end{array}$ & $10 \mathrm{~mA}$ \\
& $-\quad$ Sleep mode & $0.5 \mathrm{~mA}$ \\
& $-\quad$ Transmit mode \\
& $-\quad$ Listen mode \\
& $-\quad$ Passive mode & $10 \mathrm{~mA}$ \\
& $\begin{array}{l}\text { Kapasitas baterai source } \\
\text { node }\end{array}$ & $40.01 \mathrm{~mA}$ \\
\hline 5 & $\begin{array}{l}\text { Kapasitas baterai sink } \\
\text { node }\end{array}$ & $100 \mathrm{mAh}$ \\
\hline 7 & $\begin{array}{l}\text { Panjang garis tengah } \\
\text { cluster }\end{array}$ & 60 \\
\hline 8 & Tinggi cluster & $0.987 * 60$ \\
\hline 9 & Luas jaringan & $300 \mathrm{~m}^{2}$ \\
\hline 10 & Jumlah node & 300 node \\
\hline
\end{tabular}

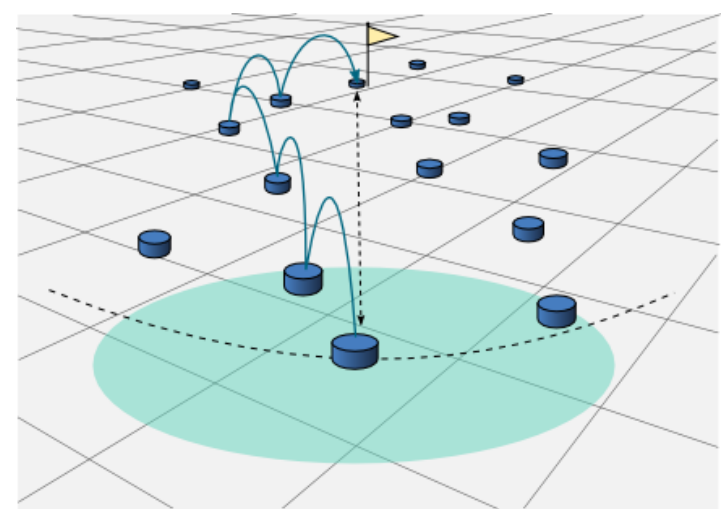

Gambar 3. SGP Dengan Teknik Greedy Routing. (Sarkar, 2010)

\section{HASIL DAN ANALISA}

Simulasi dilakukan dengan menggunakan SIDnet SWANS Simulator, yang merupakan simulator khusus WSN. SIDnet SWANS dikembangkan oleh Northwestern University, dan berjalan di atas JiST/SWANS (Java in Simulation Time / Scalable Wireless Ad Hoc Network Simulator). Sistem operasi yang digunakan adalah Windows 10 dengan 6 GB RAM. Jumlah node yang digunakan adalah 300 node dengan luas jaringan 300 $\mathrm{m}^{2}$, dan ditempatkan secara acak.

Hasil simulasi dibandingkan dengan protokol SGP (tanpa clustering, tanpa mekanisme pengiriman adaptif), SGP-adaptive (tanpa clustering, dengan pengiriman adaptif), C-SGP non-adaptive (dengan clustering, tanpa pengiriman adaptif), dan C-SGPrandom (pemilihan cluster head dibuat random).

\subsection{Hasil Perbandingan Network Lifetime}

Hasil simulasi menunjukkan bahwa protokol C-SGP memiliki network lifetime tertinggi dibandingkan protokol pembanding. Peningkatan
25,68\% terjadi jika bandingkan dengan protokol SGP adaptive seperti tercantum pada Gambar 4.

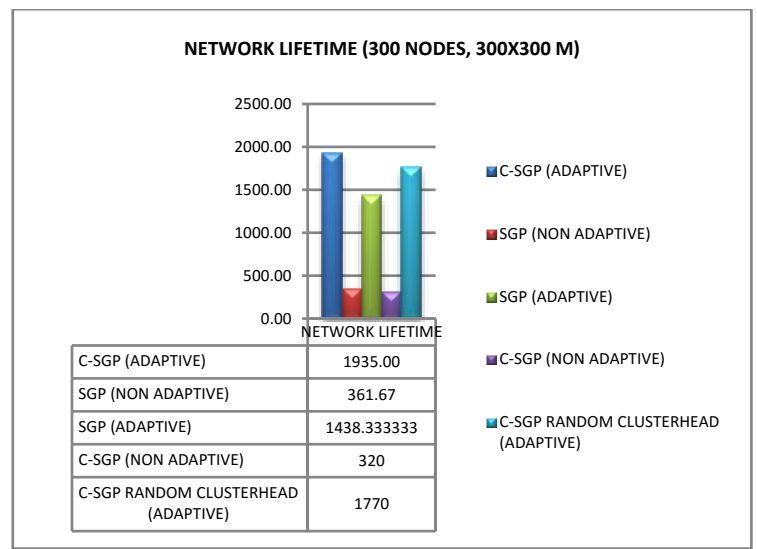

Gambar 4. Perbandingan Network Lifetime

Tingginya network lifetime adalah karena pada protokol C-SGP tidak semua node terlibat dalam proses forward data, sebab data hasil pemindaian dikirim ke cluster head sehingga proses transmisi data lebih terlokalisir. Mekanisme pengiriman yang adaptif juga mengurangi jumlah transmisi secara drastis, tanpa mengabaikan data-data dengan prioritas tinggi.

\subsection{Hasil Perbandingan Packet Delivery Ratio (PDR)}

Packet Delivery Ratio adalah rasio antara jumlah data yang dikirim dengan data yang diterima oleh sink. Dalam protokol routing berbasis cluster, data yang dihitung sebagai data kirim adalah data yang dikirim oleh cluster head. Dari hasil simulasi, PDR dari protokol routing $C-S G P$, relatif tinggi jika dibandingkan dengan protokol pembanding, seperti divisualisasikan pada Gambar 5.

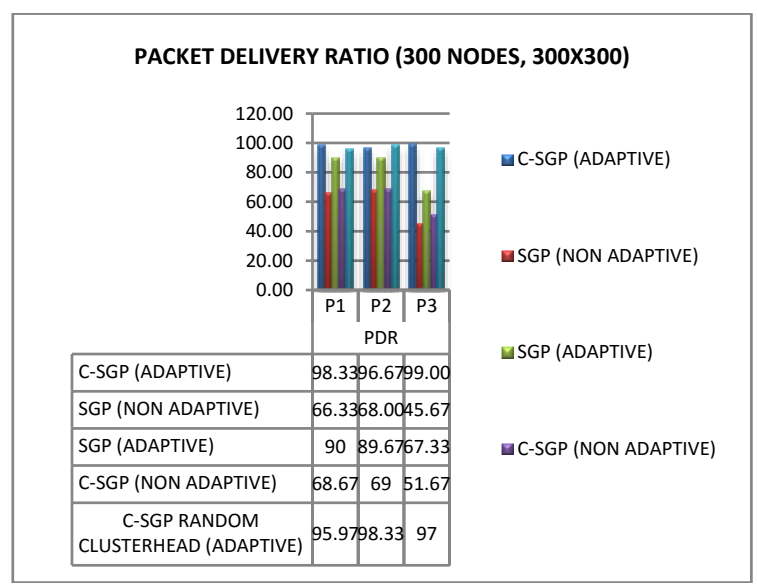

Gambar 5. Perbandingan Packet Delivery Ratio

\subsection{Hasil Perbandingan Latency}

Latency adalah rentang waktu yang diperlukan mulai paket dikirim hingga paket diterima oleh sink. Menurut hasil simulasi, latency protokol C-SGP relatif rendah jika dibandingkan dengan protokol pembanding. Hal ini disebabkan oleh proses 
pengiriman adaptif yang diterapkan mengurangi jumlah transmisi, yang pada akhirnya turut mengurangi kesibukan jaringan sehingga tabrakan data juga berkurang.

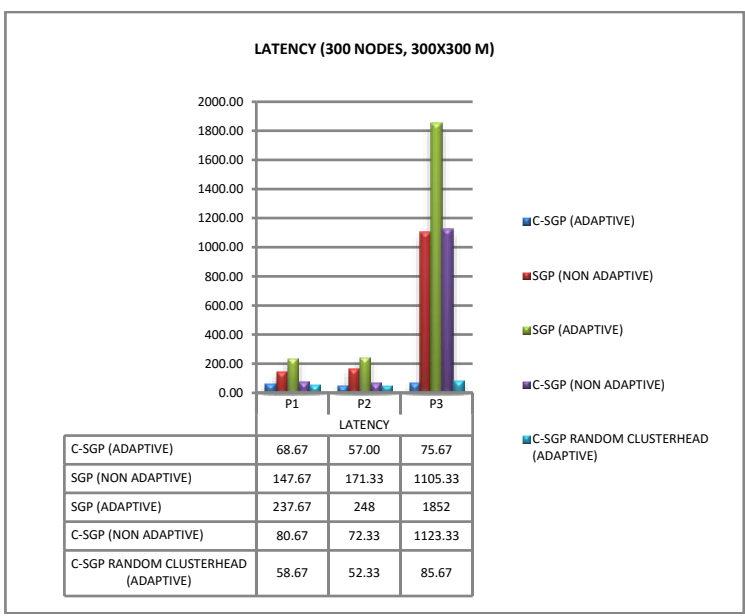

Gambar 5. Perbandingan Latency

\section{KESIMPULAN}

Pengembangan protokol routing C-SGP dilakukan dengan cara memodifikasi protokol routing SGP. Modifikasi dilakukan dengan menambahkan tahapan clustering, dimana jaringan dibagi menjadi beberapa cluster berbentuk segi enam berdasarkan informasi geografis jaringan. Pemilihan cluster head dilakukan dengan mencari node yang memiliki posisi paling tengah atau paling dekat dengan titik tengah geografis cluster.

Dari hasil uji coba, protokol C-SGP terbukti meningkatkan network lifetime dibandingkan dengan SGP (tanpa clustering, tanpa mekanisme pengiriman adaptif), SGP-adaptive (tanpa clustering, dengan pengiriman adaptif), C-SGP non-adaptive (dengan clustering, tanpa pengiriman adaptif), dan C-SGPrandom (pemilihan cluster head dibuat random).

\section{SARAN}

Perlu dilakukan uji coba mengenai penentuan kepadatan jaringan yang optimal untuk penggunaan protokol $C$-SGP. Uji coba ini berkaitan dengan analisa yang lebih mendalam mengenai pengaruh rasio jumlah node dan luas area jaringan terhadap network lifetime, packet delivery ratio, dan latency.

\section{DAFTAR PUSTAKA}

DIETRICH, I., \& DRESSLER, F. 2009. On the Lifetime of Wireless Sensor Network. ACM Transactions on Sensor Networks, Vol. 5, No. 1, 1-38.

GHICA, O., TRAJCEVSKI, G., SCHEUERMANN, P., BISCHOF, Z., \& VALTCHANOV, N. 2007. Demo Abstract: SIDnet-SWANS: A Simulator and Integrated Development Platform for Sensor Networks Application.
Evanston, IL, USA: Departement of EECS, Northwestern University.

HEINZELMAN, W., CHANDRAKASAN, A., \& BALAKRISHNAN, H. 2005. EnergyEfficient Communication Protocols for Wireless Microsensor Networks. Proceedings of the 33rd Hawaaian International Conference on Systems Science (HICSS).

JANNU, S., \& JANA, P. K. 2014. Energy Efficient Grid Based Clustering and Routing Algorithm for Wireless Sensor Network. Fourth International Conference on Communication Systems and Network Technologies. Dhanbad, India.

KAUR, M., \& AMARVIR, S. 2016. Detection and Mitigation of Sinkhole Attack in Wireless Sensor Network. International Conference onMicro-Electronics and Telecommunication (ICMETE). Ghaziabad, India.

Engineering

LEE, J. S., \& KAO, T. Y. 2016. An Improved Three-Layer Low-Energy Adaptive Clustering Hierarchy for Wireless Sensor Networks. IEEE Internet of Things Journal, 951-958.

MAGHSOUDLOU, A., ST-HILAIRE, M., \& KUNZ, T. 2011. A Survey on Geographic Routing Protocols for Mobile Ad Hoc Networks. Technical Report SCE-11-03, Carleton Unversity.

RAJAGOPALAN, R., \& VARSHNEY, P. K. 2006. Data Aggregatin Techniques in Wireless Sensor Network: A Survey. IEEE Communications Surveys and Tutorials, 4863. 